\title{
Swelling properties of a Danish Paleogene clay: a multiscale study on structure
}

\author{
Giorgia Di Remigio ${ }^{1, *}$, Irene Rocchi ${ }^{1}$, Varvara Zania ${ }^{1}$ \\ ${ }^{1}$ Technical University of Denmark, Department of Civil Engineering, DTU
}

\begin{abstract}
Paleogene clays are highly plastic, stiff clays deposited between 65.5 and 43 millions of years ago, frequently met in northern Europe. As they were deposited before the Quaternary, they experienced the glacial cycles that occurred in that period. The evolution and movement of the ice masses above the Paleogene clays highly influenced their stress history. During the interglacial periods the glaciers melted, unloading the underlying formations while during the glacial periods the glaciers mass loaded the Paleogene clays and sheared their shallower layers. Previous studies examined the compressibility and swelling of Danish Paleogene clays, and showed an early preconsolidation stresses, lower than that associated with the overburden pressure. This phenomenon was attributed to the effects of the glaciers movements. Other factors that have not been investigated yet and influence the deformation behaviour, can be associated with the micro and nano structure, meaning the particle orientation, and the mineralogical composition of the clays. This study focuses on a Danish Paleogene Formation called Røsnæs clay and the aim is to investigate the macromechanical swelling behaviour and its relation with particle rearrangement. A combination of 1D compression tests, microscopy imaging, mercury intrusion porosimetry and X-ray diffraction tests were performed on reconstituted and undisturbed samples in order to investigate the fabric, the pore structure and the mineralogy of the soil. A synthetic saline solution reproducing the in situ water was used to prepare the reconstituted samples and for the water bath. Variations with the swelling index were correlated with the clay particles rearrangement taking in to account the mineralogical composition. The compression curves and the scanning electron microscope micrographs were correlated with the mercury intrusion porosimeter results.
\end{abstract}

\section{Introduction}

A multiscale approach has been developed in the last decades in order to investigate the mechanical behaviour of soils. Vitone et al. [1] studied the plane strain behaviour of highly fissured scaly Apenninic clays with the use of False Relief Stereophotogrammetry. The meso and micro structures of a Pleistocene stiff clay were investigated by Cotecchia et al. [2] with the use of Scanning Electron Microscopy (SEM). They studied the reorientation of the clay particles at different 1D strain. Moreover, SEM was used by Gasparre et al. [3] to show the different fabric features in London Clay units. Furthermore, Fearon and Coop [4] investigated the influence of different remoulding methods on a natural material by the use of SEM. In association with this technique, Delage and Lefebvre [5] used Mercury Intrusion Porosimeter (MIP) to investigate the evolution of the nanoscale pore structure of a sensitive clay during consolidation. At an even lower scale ( $\AA$ ), the clay minerals are studied. Different clay minerals have distinct mechanical responses due to their peculiar interaction with water. It is well known that, contrary to illite and kaolinite, smectite is highly prone to swell as indicated by its high plastic index. According to Laird
[6], the smectites swelling is due to the assimilation of solvents between the smectite layers and to the replacement of interlayer cations by larger organic or polymeric hydroxyl-metal cations, so that the presence of different salts in the environment can lead to different mechanical responses. In particular, Chatterjee et al. [7] determined the activity of the exchangeable cations in a monohydrated 2:1 dioctahedral smectite, determining $\mathrm{Ca}^{2+}$ as the most active and $\mathrm{K}^{+}$as the least active exchangeable cation.

Smectite rich clays can be found in the North Sea Basin as an intense volcanic activity and massive volcanic ash deposition took place in the surrounding area at the time of deposition. As described by several authors (e.g. [8], [9], [10]), the North Sea Basin started developing during the Early Cretaceous and kept evolving during the Paleogene. In this period, the Scandinavian region uplift began, increasing the amount of sediments depositing in the centre of the basin. Moreover, the basin experienced several sea level regressions and transgressions cycles. For these reasons, according to Heilmann-Clausen et al. [11] and Schmitz et al. [12], the Paleogene clays deposited in this area during the Early Eocene, such as the London Clay in England, the Ieper (or Ypres) Formation in Belgium and

\footnotetext{
* Corresponding author: gidire@byg.dtu.dk
} 
the Røsnæs Clay in Denmark, show common features. Nevertheless, because of their different content of coarse grain and glauconitic facies, they are classified with different names.

This paper presents an investigation of the 1D swelling behaviour of the Røsnæs Clay Formation. A series of experiments on both reconstituted and undisturbed samples retrieved from the Fehmarn Belt area, were performed in order to investigate the effects of the geological history on the swelling behaviour of the clay. Last, the obtained data concerning the macro mechanical behaviour of the Røsnæs Clay were interpreted by analysing the microscopic structure at different loading steps. More specifically, Scanning Electron Microscopy images and Mercury Intrusion Porosimetry tests were used. The mineralogical composition was investigated with the use of X-Ray Diffraction (XRD) tests.

\section{Material tested}

A simplified geological profile of the Fehmarn Belt area, where the construction of a subsea immersed tunnel linking Germany and southern Denmark is planned, is given in Fig.1. The prevailing Paleogene clay in this profile is Røsnæs Clay, which is a 52 million years old highly calcareous, highly plastic, fine grained, fissured clay formation, overlaid by further Paleogene Clays and glacial sediments. The presence of strongly variable seawater currents affected the depositional process of the Røsnæs Clay Formation so that the lithostratigraphy can change significantly throughout its geological members. For this Formation, Heilmann-Clausen et al. [11] highlighted the presence of 7 depositional members, having different mineralogical composition. In particular, they have different volcanic ash, organic material, iron and carbon contents. Several semiquantitative X-Ray Diffraction analyses were carried out by Awadalkarim [15] in order to investigate the mineralogy of the different Paleogene Clays retrieved in the Fehmarn Belt. For the Røsnæs Clay Formation, he estimated a smectite content of $15-55 \%$, an illite content of $30-55 \%$ and a kaolinite content of the $10-35 \%$ of the total dry weight. In addition, a shallow sheared (or "folded") layer can be found throughout the whole Røsnæs Clay Formation.

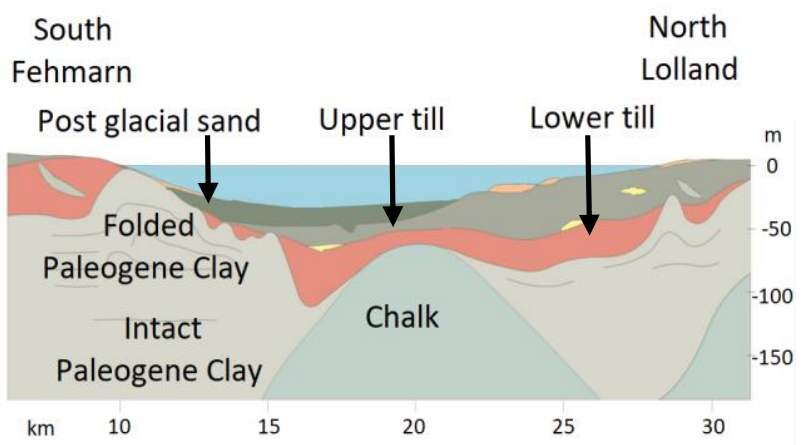

Fig. 1. Simplified geological profile across Fehmarn Belt. The folds indicate the folded Paleogene Clay although the real pattern is supposed to be much more intense and complex. (Modified after [13]).
This was developed as a consequence of the glaciotectonic movements, which occurred during the Quaternary. The ice masses moved on the deposits and deformed the underlying Paleogene layers shearing them. As it might be expected, the samples retrieved from the intact layer of the Røsnæs Clay Formation are characterized by a stiffer behaviour than those retrieved from the folded layer as showed by Rocchi et al. [14]. In their work, they performed a series of one-dimensional consolidation (ILO) tests on undisturbed samples of folded and intact Røsnæs Clay using different salinity levels in the bath water. As this investigation was only at the macro scale, the authors suggested that a mineralogical and sub-cm scale investigation is necessary for a more systematic interpretation of the ILO tests.

\section{Methodology}

In the current study, a series of ILO tests were performed on rotary-cored Folded Røsnæs Clay samples retrieved at about 59.4 meters depth from the seabed. In order to reach a maximum stress similar to the preconsolidation stress expected from the geological history of this Formation (ca. 5-8 MPa [14]), a $50 \mathrm{~mm}$ fixed ring was used. At lower stresses, the tests were performed with a $60 \mathrm{~mm}$ diameter floating ring. Both reconstituted and undisturbed samples were tested. Each load step lasted at least 24 hours, guaranteeing full consolidation. The undisturbed samples (U) used for the fixed ring oedometer were trimmed in the cutting ring and installed, while those used for the floating ring were sampled with the help of a sharp edge sampler and a cutter and subsequently extruded. Once the specimen was installed into the oedometer, it was loaded at constant height to the in situ stress $\left(\sigma^{\prime} \approx 400 \mathrm{kPa}\right)$ to avoid any swelling due to the absorption of the water stored in the porous stone. After that, the cell was filled with synthetic water reproducing the chemical composition of the Røsnæs Clay's pore water as determined by the Geological Survey of Denmark and Greenland (GEUS). In regards to the reconstituted samples (R), they were prepared remoulding the trimmings obtained during the preparation of the undisturbed samples. As per Burland [16] a synthetic saline water was added to reach a water content of 1.5 times the liquid limit.

Table 1 shows a summary of the performed tests. The code is DD.DD_S1_S2_St where DD.DD is the depth, $\mathrm{S} 1$ is the maximum applied stress (MPa), S2 is the stress the ILO tests were interrupted and the water bath was emptied (MPa) and St is the state of the soil, whether is reconstituted or undisturbed. At the end of the test, the water bath was emptied and the specimen was quickly disassembled. Right after, half of the specimen was sealed with a plastic film in order to preserve its water content. This was then used to obtain samples for imaging with a Quanta FEG 200 ESEM using the SEM mode. The samples were mechanically fractured in order to obtain fresh exposed surfaces and mounted in the ESEM without any freeze drying or coating. 
Table 1. Summary of the performed tests. *These tests were performed on the 59.50_7_0.4_U trimmings.

\begin{tabular}{|c|c|c|c|c|c|}
\hline & $\begin{array}{c}59.38 \\
-2 \_2 \\
-\bar{U}^{2}-\end{array}$ & $\begin{array}{l}59.42 \\
2 \text { 2_0. } \\
6 \text { 6_U }\end{array}$ & $\begin{array}{c}59.46 \\
222 \\
-{ }_{U}\end{array}$ & $\begin{array}{r}59.50 \\
7 \_0 . \\
-{ }_{4}-\mathbf{U}\end{array}$ & $\begin{array}{r}59.50 \\
7{ }^{7} 0 . \\
007 \_R\end{array}$ \\
\hline $\mathrm{e}_{0}$ & 1.04 & 1.00 & 1.01 & 1.01 & 4.37 \\
\hline w0 & 0.337 & 0.337 & 0.337 & 0.343 & 1.52 \\
\hline $\mathrm{z}[\mathrm{m}]$ & 59.38 & 59.42 & 59.46 & 59.50 & 59.50 \\
\hline $\begin{array}{l}\sigma_{\mathrm{v}}^{\prime} \max \\
{[\mathrm{kPa}]}\end{array}$ & 2000 & 2000 & 2000 & 7000 & 7000 \\
\hline $\begin{array}{l}\sigma_{\mathrm{v}}^{\prime} \text { final } \\
{[\mathrm{kPa}]}\end{array}$ & 2000 & 600 & 2000 & 400 & 7 \\
\hline efinal & 0.877 & 0.911 & 0.885 & 0.821 & 1.234 \\
\hline $\begin{array}{l}\text { Ref. point } \\
\text { (Fig. 3) }\end{array}$ & 3 & 2 & 2 & $4\left(1^{*}\right)$ & 5 \\
\hline $\mathrm{WL}_{\mathrm{L}}$ & 106 & - & 104 & - & - \\
\hline WP & 43 & - & 36 & - & - \\
\hline $\mathrm{G}_{\mathrm{s}}$ & 2.82 & 2.85 & 2.91 & 2.85 & 2.85 \\
\hline SEM & $\begin{array}{c}x 250 \\
x 7000\end{array}$ & $\begin{array}{c}x 250 \\
x 7000\end{array}$ & $\begin{array}{c}x 250 \\
x 7000\end{array}$ & $\begin{array}{c}x 250 \\
x 7000\end{array}$ & $\times 7000$ \\
\hline
\end{tabular}

To guarantee the repeatability of the observed features, each ILO sample was imaged taking 6 different sub-samples from different areas of the sample, 3 in each direction. The micrographs were taken with a spot opening of 3.0, at a working distance of $8-10 \mathrm{~mm}$ and with an electric potential difference of $20-30 \mathrm{kV}$.

A series of MIP tests were also performed. One quarter of the oedometer specimen was sealed at the end of the ILO test as for the SEM. A piece having approximate dimensions of $5 \times 5 \times 10 \mathrm{~mm}^{3}$ was obtained from each sealed specimen. The sub sample was oven dried at $60^{\circ} \mathrm{C}$ for 2 days before testing.

A series of semi-quantitative X-Ray Diffraction analyses were carried out in order to guarantee consistency in the mineralogy of the tested material. About 10 grams of soil were taken from the trimmings of each specimen. Afterwards, the salt was removed from the sample and a bulk sample was tested. Then, the material was sieved with a $45 \mu \mathrm{m}$ sieve and the passing soil was used to prepare the XRD samples using the glass slide method. Based on the XRD spectra, a semiquantitative analysis was performed. The spectra were corrected using the amplification parameters suggested by Prof. O. Bjørslev from Aarhus University [17] which were obtained based on his experience with XRD tests on Danish clays. In this study, PANalytical XPert PRO XRD machine was used.

\section{Results and discussion}

The spectra of the XRD tests are presented in Fig. 2. The different sample's spectra are identical for almost the entire range of the diffraction angle. The only appreciable difference is the higher amount of iron oxide (2\%) present in bulk samples 59.42_2_0.6_U and 59.46_2_2_U (diffraction angle $2 \theta=44.549^{\circ}$ ). However, the XRD tests on the fine fraction, are identical. The analysis shows $30 \%$ smectite content, $49 \%$ illite content,
$15 \%$ kaolinite content, $3 \%$ quartz content, $2 \%$ iron content and $1 \%$ magnesium calcite content. The larger presence of iron in 59.42_2_0.6_U and 59.46_2_2_U is not expected to modify the swelling behaviour as this element is not reactive to water.

The compression curves obtained performing the ILO tests listed in Table 1, are illustrated in Fig. 3. The compression curves are approximately parallel to each other and they overlap quite well showing similar mechanical behaviour.

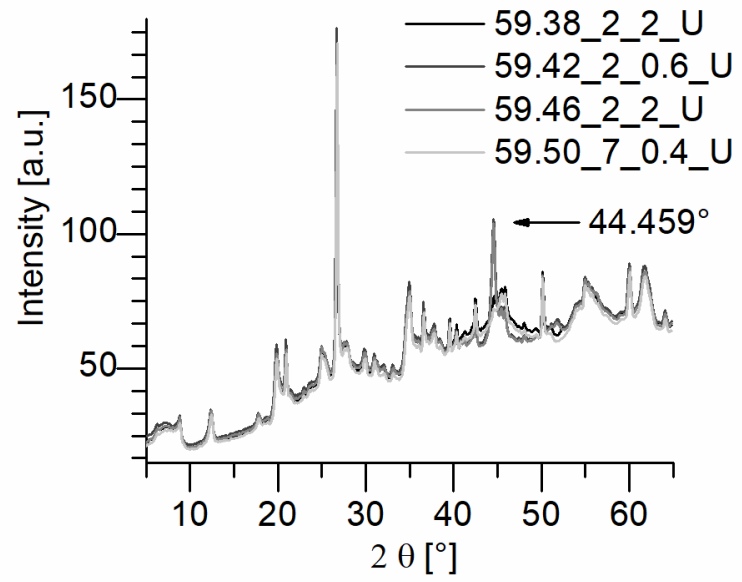

Fig. 2. Results from the XRD tests performed on the bulk material

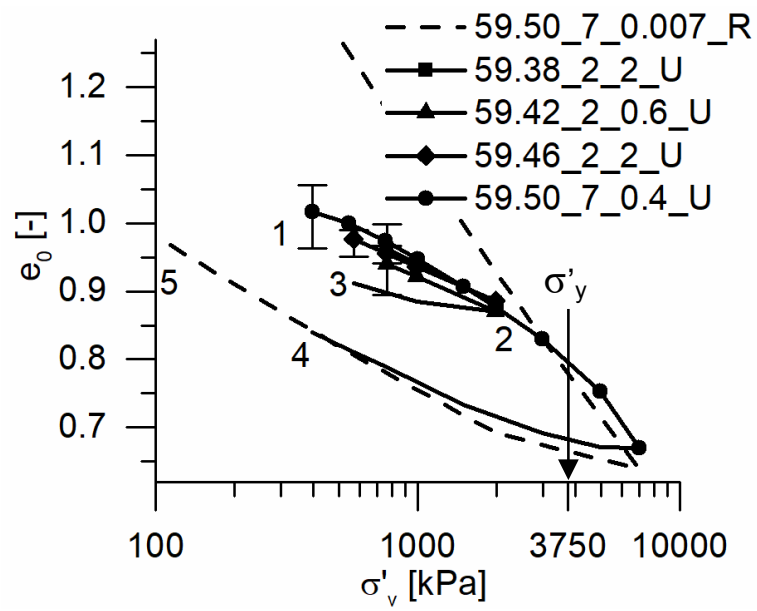

Fig. 3. Compression curves. The numbers represent the stresses at which the ILO tests were interrupted and the water bath was emptied. The samples were then unloaded, sub-sampled and imaged with SEM.

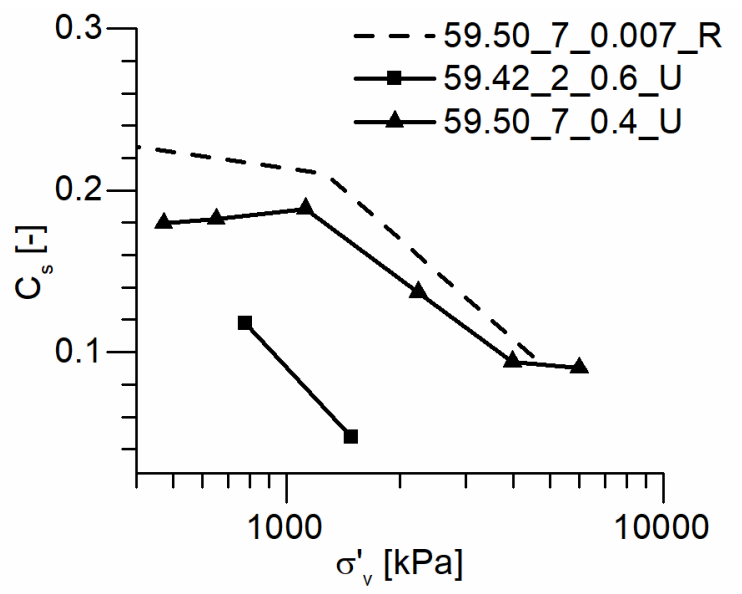

Fig. 4. Comparison of swelling indexes. 

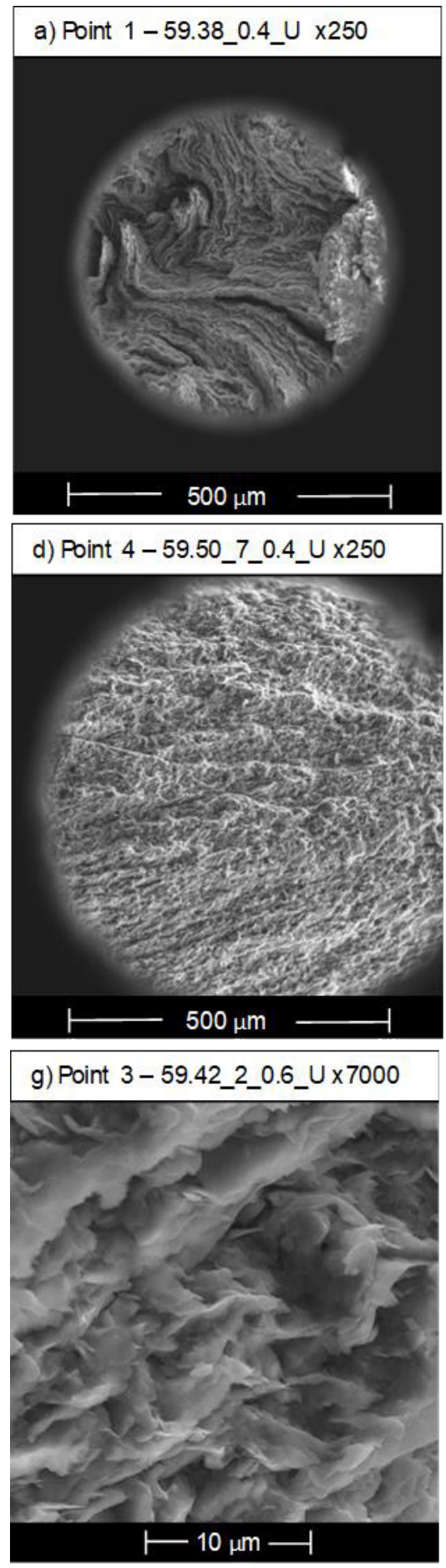

b) Point 2-59.38_2_2_U $\times 250$

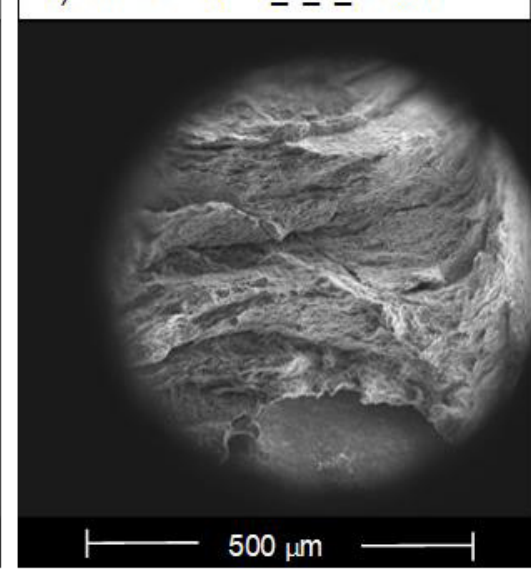

e) Point 1 - 59.38_0.4_U x7000

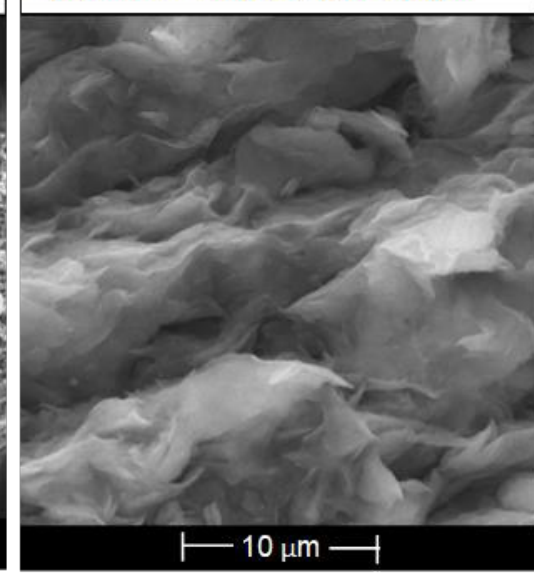

h) Point $4-59.50 \_7 \_0.4 \_U x 7000$

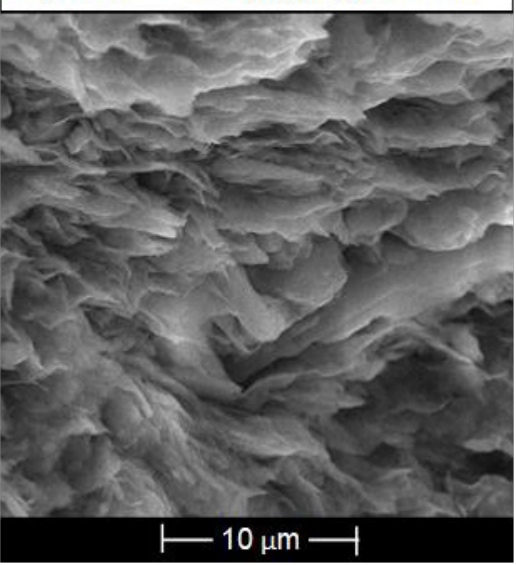

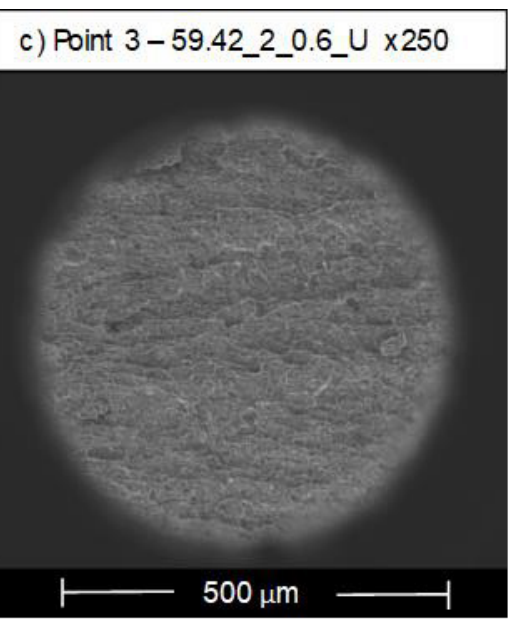
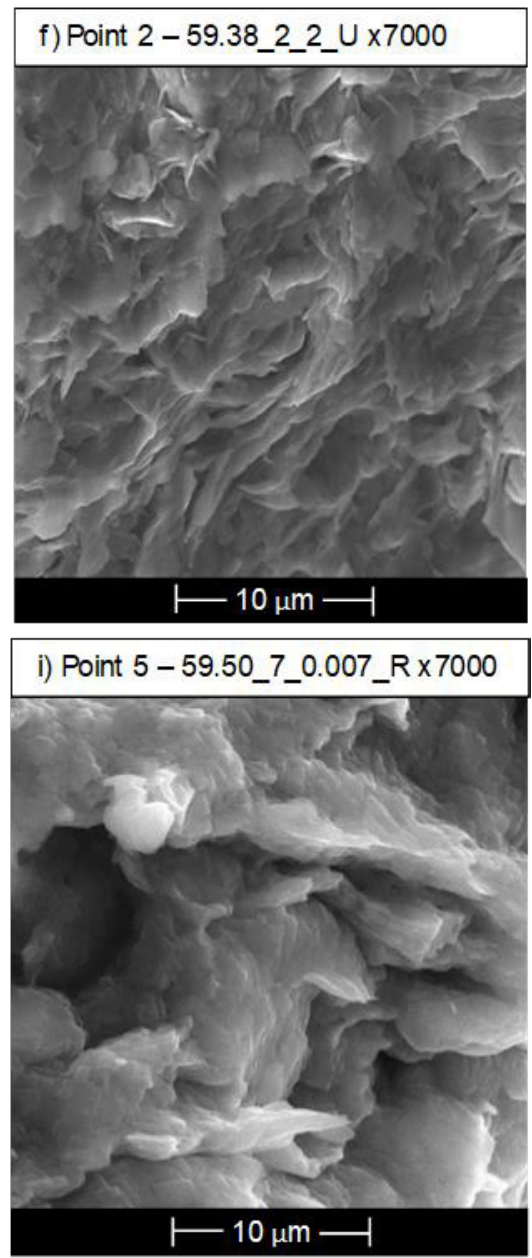

Fig. 5. An overview of the SEM micrographs. From Fig. 5.a to Fig. 5.d, micrographs at a x250 magnification are presented while from Fig. 5.e to Fig. 5.i the magnification is $\mathrm{x} 7000$.

The initial void ratio was calculated using 5 independent formulations as per Rocchi and Coop [18]. The mean value is used to plot each curve. The error bar refers to the minimum and maximum values.

Based on 59.50_7_0.4_U, a yield stress of $3.7 \mathrm{MPa}$ was estimated using the Casagrande construction. This is smaller than the 5-8 MPa expected [14] in relation to the stress history this material underwent. However, the compression curves become parallel to the ICL at about $5 \mathrm{MPa}$ consistently with the geological preconsolidation stress. Due to the test uncertainties, it is not clear whether the undisturbed samples show positive or negative sensitivity, but it is nevertheless small.

It can be noticed in Fig. 3, that the swelling curves exhibit different slopes when unloading from different stress levels. A comparison between the swelling indexes $\left(C_{s}\right)$ calculated for each unloading step is plotted in Fig. 4. The same behaviour was already observed by Rocchi et al. [14] on Røsnæs Clay and by Krogsbøll et al. [19] on another Danish Paleogene clay called Lillebælt Clay. Fig. 4 shows that the curves representing the $C_{s}$ variations are scattered but almost parallel.

In order to interpret the macroscopic mechanical 
behaviour, a series of SEM micrographs were obtained. A qualitative analysis of them is hereby performed using the nomenclature described by van Olphen [20]. The term "aggregate" is used for thick stack of flakes characterized by Face-to-Face (FF) contacts. If the structures are still characterized by FF but thin, they are called "dispersed". "Flocculated" structures present Edge-to-Face (EF) and Edge-to-Edge (EE) contacts, while, "deflocculated" structures do not. The term "domain" is used to described oriented, dispersed volumes in a structure. Fig. 5 presents SEM micrographs obtained at two different magnifications x250 (5.a-5.d) and $x 7000$ (5.e-5.i). Fig. 5.a was obtained from the trimmings of 59.38_2 2 U U. Here, the presence of folded deposition planes is clear. The same structure is partially preserved after loading at 2MPa (Fig. 5.b) but it is totally lost after swelling (Fig. 5.c and 5.d), as the swelled structure looks dispersed and homogeneously oriented on the entire sample. This suggests that swelling had a greater influence in reorienting the clay flakes than compression. At this scale, no major differences in the clay structure can be observed after swelling from either low (Fig. 5.c) or high stresses (Fig. 5.d).

Fig. 5.e shows a micrograph taken from the trimmings at a higher magnification. The particles look to be strongly aggregated with few EF and EE contacts. However, the structure looks open and characterized by cavities possibly due to the unloading process experienced during sampling and trimming. Observing Fig. 5.f, the structure looks more oriented and dispersed than compared to Fig. 5.e., without major cavities and aggregations. Fig. 5.g and Fig. 5.h show a swelled bookhouse structure, characterized by aggregated, flocculated particles. In both the micrographs, the domains appear to be more flocculated and aggregated than those in Fig. 5.f, as they show a higher number of EF contacts. The higher aggregation observed in the swelled structure could be a consequence of swelling between the single particles. Comparing the two images, swelling from high stress (Fig. 5.h) appears to result in more dispersed structure, compared to that swelled from lower stress (Fig. 5.g) where more EF contacts may be seen. It might be noticed that the folding of the depositional layers observed at low magnifications (Fig. 5.e and Fig. 5.b) are not visible at high magnifications (Fig. 5.e and Fig. 5.f). Finally, it is possible to compare the reconstituted sample in Fig. 5.i with the undisturbed samples in Fig. 5.e to Fig. 5.h. In Fig. 5.i the particle flakes are bigger and more flocculated than those observed in the undisturbed samples. Moreover, the structure is characterized by a EF contact rich, more opened structure than the undisturbed one, with obvious cavities and macro pores. Despite the differences in orientation and shape, the micrographs of the trimmings (Fig. 5.e) and those of the reconstituted sample (Fig. 5.i) are the only ones showing aggregates of comparable dimension.

While the comparison of the SEM micrographs provide an overview of the fabric, the pore structure, can be quantitatively investigated by the use of MIP.

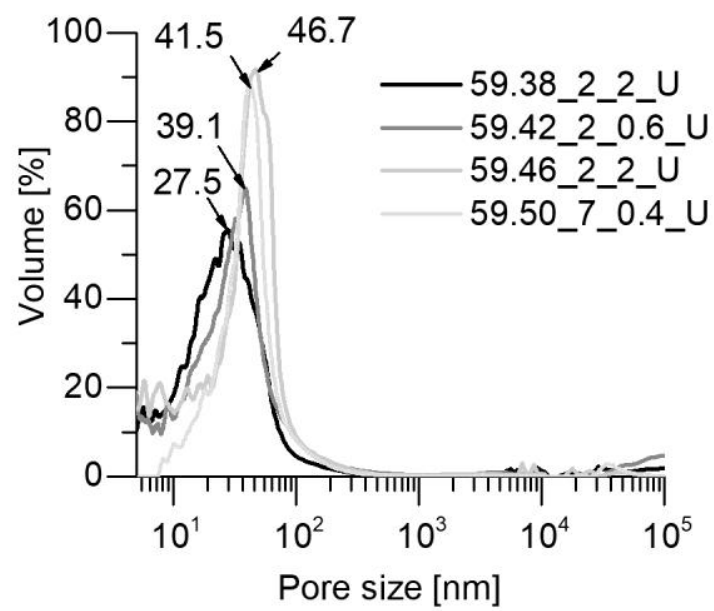

Fig. 6. Pore size distribution in undisturbed Røsnæs Clay dried samples.

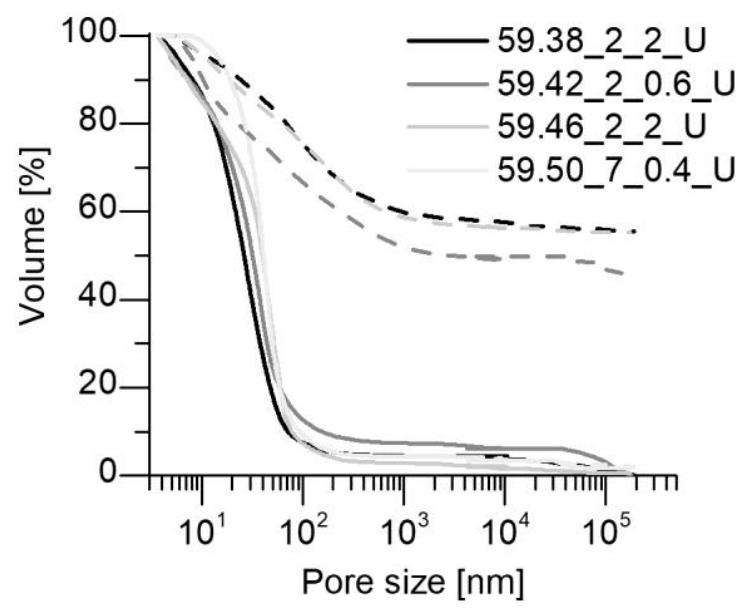

Fig. 7. Percentage of cumulative pore size distribution in undisturbed Røsnæs Clay dried samples during intrusion (solid lines) and extrusion (dashed lines). The volume is normalised over the maximum injected mercury volume.

The percentage of variation of the log differential specific intrusion volume versus the pore size distribution obtained after MIP tests is plotted in Fig. 6. The largest main void diameter is found for $59.46 \_22$ _U, followed by $59.50 \_70.4 \_\mathrm{U}$, 59.42_2_0.6_U and 59.38_2_2_U. Unexpectedly, the main void diameter distribution appears to be independent from the stress history as the two samples dismantled at $2 \mathrm{MPa}$ show both the largest and the smallest main void dimension. However, the two swelled samples show a decrease of the amount of voids below $10 \mathrm{~nm}$ compared to 59.38_2_2_U and 59.46_2_2_U. In particular, 59.50_7_0.04_U shows a complete absence of pores smaller than $\overline{5} \mathrm{~nm}$. This suggests that the swelling concurred to the reduction of the smallest pores size. Fig. 5.g and Fig. 5.h seem to support this thesis as they show swelling of the clay flakes that might have partially erased the interparticle nanometer pores. Fig. 7 plots the percentage of mercury volume intruded and extruded from the sample against the pore size diameter. Their difference represents the entrapped porosity. When intruding mercury, the whole sample porosity is filled, while in extrusion, because of the throat-pore effect, not all the mercury flows out. In Fig. 7, the two samples 
dismantled after compression at $2 \mathrm{MPa}$ show the largest trapped porosity, followed by 59.42_2_0.6_U and 59.50_7_0.4_U. This suggests, together with the observations on Fig. 6, that swelling may have altered the pore structure. In particular, Fig. 7 suggests that it leads to a more homogeneous pore size distribution, causing a reduction of the pore-throat effect and, thus, of the trapped mercury. This looks more evident for 59.50_7_0.4_U as it has a mono-dimensional pore distribution in Fig. 6 and it does not show any hysteresis during intrusion and extrusion in Fig. 7. Moreover, the fact that the sample was loaded at a stress similar to the geological one, is suspected to have had a strong influence in the homogenization of the pore size distribution. Indeed, 59.42_2_0.6_U shows a reduction of the hysteresis if compared to the other samples compressed at $2 \mathrm{MPa}$. However, this decrease is small if compared to that observed for 49.50_7_0.04_U. These observations suggest that either the stronger swelling action, the compression at stresses similar to the geological one or a combination of these two actions have an influence in the redistribution of the pore sizes. A MIP test performed on a sample obtained by an ILO dismounted at $7 \mathrm{MPa}$ is needed in order to further clarify the evolution of the pore distribution.

\section{Conclusions}

This paper presented the results obtained performing a multiscale investigation on a highly plastic Danish Paleogene clay called Røsnæs Clay. This Formation underwent million years of glaciers movements so that it can be divided into a folded and an intact layer. The results hereby reported were obtained testing folded Røsnæs Clay samples. ILO, SEM, MIP and XRD tests were performed in order to examine the samples from the macro to the nano scale taking in consideration the variation of the mineralogy. The XRD results showed a homogeneity in the mineralogy of the tested samples. Consistently, a good uniformity in compression was evident from the ILO compression curves, while in swelling at different stress, variations in the $C_{s}$ were observed. This is in accordance with the literature. Due to the tests uncertainties, it is not possible to state whether the tested samples show a positive or negative sensitivity, but this is nonetheless small.

From a microscopic point of view, the SEM images showed well oriented microstructure. The $\mathrm{x} 7000$ magnified micrographs suggest that the undisturbed structure is already well arranged and that any further reorientation of the particles is marginal. The compressed samples showed a more dispersed and deflocculated structure than those swelled from the same maximum stress. Also, samples swelled at lower stresses, showed a structure characterized by a higher presence of EF and EE contacts. The $\mathrm{x} 250$ magnification shows the presence of a folded structure not visible at higher magnifications. This looks to be partially erased during compression and entirely during swelling. This suggest that swelling is more efficient than compressing in the reorientation process. MIP results are consistent with what observed in the SEM images. A mono dimensional pore size distribution was observed for 59.50_7_0.4_U. This is suspected to be linked either to a collapse of the smaller pores after loading the sample above the geological pre stress or to the interparticle swelling of the clay flakes. Further investigations at higher stresses are necessary to achieve a better understanding of the behaviour of the Røsnæs Clay Formation.

\section{References}

1. C. Vitone, F. Cotecchia, J. Desrues, G. Viggiani, Soils found., 49, 3, 355-368 (2009)

2. F. Cotecchia, F. Cafaro, S. Guglielmi, Proc. Eng., 158, 57-62 (2016)

3. A. Gasparre, S. Nishimura, M. R. Coop, R. J. Jardine, Géotechnique, 57, 1, 19-31 (2007)

4. R. E. Fearon, M. R. Coop, Géotechnique, 50, 4, 471-477 (2000)

5. P. Delage, G. Lefebvre, Can. Geotech., 21, 21-35 (1984)

6. D. A. Laird, Appl. Clay Sci., 34, 74-87 (2006)

7. A.Chatterjee, T. Ebina, Y. Onodera, F. Mizukami, J. Chem. Phys., 120, 3414-3424 (2004)

8. G. Sclater, P. A. F. Christie, J. Geophys. Res., 85, B7, 3711-3739 (1980)

9. P. Barton, R. Wood, Geophys. J. R. Astron. Sot., 79, 987-1022 (1984)

10. J. A. Thorne, A. B. Watts, Am. Assoc. Pet. Geol. Bull., 73, 88-116 (1989)

11. C. Heilmann-Clausen, O. B. Nielsen, F. Gersner, Bull. Geol. Soc. Den., 33, 3-4, 287-323 (1985)

12. B. Schmitz, C. Heilmann-Clausen, C. King, E. Steurbaut, E.P. Andreasson, R. M. Corfield, J. E. Cartlidge, Geol. Soc. Spec. Publ., 101, 275-306 (1996)

13. Rambøll/Arup 2011. Summary of geological conditions. (GDR 01.3-002, 2011)

14. I. Rocchi, G. Di Remigio, G. L. Grønbech, V. Zania, Proc. Mic.-Mac. Math. Mod. Soil. Mech, (2018)

15. A. Awadalkarim, Petrophysics of Palaeogene sediments. (DTU, 2014)

16. J. B. Burland, Géotechnique, 40, 3, 329-378 (1990)

17. E. N. Mbia, Assessment of Dynamic Flow, Pressure and Geomechanical Behaviour of a CO2 Storage Complex (DTU, 2014)

18. I. Rocchi, M.R. Coop, Geot. Test. J., 37, 1, 169-175 (2014)

19. A. Krogsbøll, O Hededal, N. Foged, Proc. 16th Nord. Geomech. Meet. NGM, 1, 133-140 (2012)

20. H. van Ophen, Clay Colloid Chemistry (WileyInterscience publication, John Wiley \& Sons, 1977) 